\title{
Reflexiones para una educación ético-estética de la belleza que contribuye a la dignificación de la persona en el deporte
}

\author{
Reflections on ethical-aestbetic education in beauty \\ contributing to the promotion of the dignity of the sportsperson
}

ANTONIO SÁNCHEZ PATO Y FRANCISCO DE LA TORRE OLID

Universidad Católica de Murcia (España)

Artículo recibido: 17 septiembre 2015

Solicitud de revisión: 14 octubre 2015

Artículo aceptado: 14 enero 2016

Resumen

Desde la teología y la filosofía podemos comprender el concepto de belleza en el deporte ligado a la dignidad humana. Para ello, en este artículo: $a$ ) analizamos desde la antropología cristiana el lugar del cuerpo y el valor del deporte en la vida del ser humano; $b$ ) abordamos la estética intentando comprender la belleza ligada a la dignidad; a continuación, c) proponemos una educación estética donde la belleza ligada al deporte no está exenta del sufrimiento, de las limitaciones físicas o psíquicas del individuo, para que seamos capaces de ver más allá de las formas, en orden a respetar y salvaguardar la dignidad de la persona humana; finalmente, $d$ ) reflexionamos sobre el concepto de belleza que los profesores y los entrenadores están trasmitiendo a los alumnos y a los deportistas a través del deporte, proponiendo un modelo en el que tienen cabida el dolor, el sufrimiento, las limitaciones e imperfecciones, sin dejar por ello de ser bello.

Palabras clave: deporte, educación, ética, estética, belleza, dignidad

\begin{abstract}
From theology and philosophy we can understand the concept of beauty in sport linked to human dignity. Therefore, in this article: $a$ ) we analyze, from the anthropology of Christianity, the body and the value of sport in the lives of human beings; $b$ ) we boarded the aesthetic trying to understand beauty linked to dignity; then $c$ ) we propose an aesthetic education where beauty linked to sport is not without suffering, physical or mental limitations of the individual, so that we are able to see beyond the forms, in order to respect and safeguard the dignity of the human person; finally, $d$ ) we reflect on the concept of beauty that teachers and coaches are transmitting to students and athletes through sport, proposing a model that fits the pain, suffering, limitations and imperfections while still being beautiful.
\end{abstract}

Keywords: sport, education, ethics, aesthetics, beauty, dignity 


\section{INTRODUCCIÓN: LAS VIRTUDES Y EL DEPORTE}

El cuerpo es el templo del conocimiento existencial y experiencial del ser humano. Un ser que está abocado a la existencia, a vivir fuera de sí mismo y a edificarse a través de su experiencia. En esta vivencia, el cuerpo se erige como canal fundamental, porque el hombre vehicula su existencia a través de su corporeidad. Una de sus formas adquiere un sentido especial a través de la práctica deportiva, porque: «El deporte es una realidad metafísica del hombre. Es decir, que dondequiera que se da el hombre, se da el deporte, y solo en el hombre se puede este concebir» (Cagigal, 1959).

El deporte y el deportista, a través de la práctica, se convierten en un camino de renuncia y sacrificio propio del asceta. La ascesis, está constituida por una serie de reglas y prácticas encaminadas a la liberación del espíritu y al logro de la virtud, porque el ascetismo es un «ejercicio de entrenamiento», que los monjes tomaron de los atletas griegos (Ortega y Gasset, 1996). Todos los deportes implican (Juan Pablo II, 1980: 1678):

\footnotetext{
El dominio de las propias facultades, el concepto de la lealtad, la aceptación de las reglas, el espíritu de renuncia y de solidaridad, la fidelidad a los compromisos, la generosidad con los vencidos, la serenidad en la derrota, la paciencia con todos...: son un conjunto de realidades morales que exigen una verdadera ascética y contribuyen eficazmente a formar al hombre y al cristiano.
}

En la cultura griega clásica, la virtud se entendía como areté, la cual constituía el ideal de la paideia, esto es, la educación integral del hombre, donde la práctica deportiva ocupaba un lugar privilegiado. Este ideal comprendía la fusión de lo bello y lo bueno, la kalokagathía. "Kalos es aquello digno de reconocimiento en virtud de su apariencia, aquello excelso por ser hermoso» (Siabra, 2007: 1).

A diferencia del kalos, el agatbos se refería más a la naturaleza de la persona que a su aspecto. Sin embargo, en el mundo homérico esa eminencia de naturaleza tiene que ser manifestada, por lo que «tener arete, parecer kalos y ser agatbos eran una y la misma cosa» (Siabra, 2007: 2).

El deporte, desde una perspectiva cristiana, no solo modela el cuerpo, sino también el espíritu del hombre. Juan Pablo II, en el Jubileo a los deportistas (2000), ya nos exhortaba a considerar el deporte como portador y comunicador de valores muy profundos: elevados ideales humanos y espirituales, basándose en el respeto a las reglas, pero, sobre todo, tomando como centralidad a la persona humana. Por ello, aunque en el deporte no 
deben olvidarse las ricas posibilidades físicas del hombre, también deben destacarse en él sus capacidades intelectuales y espirituales.

Según Carol Wojtyla, el verdadero atleta no debe dejarse llevar por la obsesión de la perfección física, ni por principios utilitaristas ni hedonistas. Deben prevalecer en la práctica deportiva valores de fraternidad, magnanimidad, honradez y respeto del cuerpo, haciendo del deporte un medio y no un fin. El deporte tiene sus propios riesgos - mortificación del cuerpo, búsqueda del lucro, enfrentamiento, etc.- que pueden hacer perder de vista el objetivo del cristiano: perseguir una corona, no una cualquiera, sino «la que no se marchita» (San Pablo, Co 9, 25).

Lo que está en juego en el deporte, es una educación en las virtudes humanas, de los ideales de lealtad, perseverancia, amistad, solidaridad y paz. Esto es, un deporte entendido como medio educativo para el hombre, con relativa importancia en la vida del individuo, que ayude en la formación equilibrada de la persona (Quintana, 2001). Porque más allá de las capacidades físicas y técnicas, Juan Pablo II (2004: 80) identifica aquellos valores auténticos de la vida como claves ejemplares del desempeño deportivo, «el amor a la verdad y la justicia, el gusto por la belleza y la bondad, la búsqueda de la auténtica libertad y de la paz», retomando las palabras de Juan XXIII (1959: 280): «también en el deporte, pueden encontrar desarrollo las verdaderas y fuertes virtudes cristianas [...] la caridad, el amor de fraternidad, el respeto reciproco, la magnanimidad».

Para Juan Pablo II, la dimensión agonística que caracteriza al deporte es un medio de entrenamiento espiritual y de «exaltación de auténticas virtudes humanas» (1981: 16), un ejercicio ascético (1988) que prepara al cristiano para las exigencias de la vida cristiana: «disciplina, fuerza de voluntad, fidelidad a los propios deberes, espíritu de sacrificio y capacidad de sufrir» (1995: 3), no solo para ser el mejor, sino «en vista de una formación completa de la persona» (1981: 16).

Para ello, es necesario que el deporte sea vivido como una gimnasia del cuerpo y del espíritu, "como un compromiso constructivo de fortaleza, templanza, prudencia y justicia, convirtiéndose en ejemplo de virtud» (1987: 20); para ser campeón tanto en el deporte como en la vida, porque «el deporte es escuela de vida»(1995: 3).

En esta línea, el papa Benedicto XVI, con motivo de los Juegos Olímpicos de Londres 2012, destacó que deberían ser una verdadera experiencia de hermandad entre los pueblos, puesto que son el mayor evento deportivo mundial, con un fuerte valor simbólico, y que debido al espíritu de la 
Tregua Olímpica, deben promover la paz y la reconciliación en todo el mundo.

\section{PROBLEMÁTICA: ESTÉTICA, BELLEZA Y DIGNIDAD}

Cuando abordamos el tema del cuerpo, ligado al deporte y a la religión, emerge una intersección con respeto a la belleza que es preciso analizar. La belleza, que para Patrício (1993: 118) es la propia verdad en su esplendor, se encuentra en el deporte ligada al cuerpo: «la belleza es el esplendor de la Verdad. También se puede enunciar así: la Belleza es la Verdad en su esplendor. Esta segunda formulación [...] coloca bien a la vista la identidad de la Belleza y de la Verdad». Se trata de un concepto que debe ser compatible con la dignidad humana, la dignitas. En este sentido, todas las reflexiones ético-antropológicas de Karol Wojtyla «expresan una atención sobre la corporeidad humana que es camino para resaltar la dignidad de la persona» (Hernández, 2004: 432). A su vez, este concepto de dignidad se presenta como necesario, asumiendo que es indeterminado, complejo y abstracto; si bien su exigencia está salvada al ser proclamado el compromiso iusnaturalista por parte del legislador constituyente que preserva la dignidad humana con un cuadro de derechos fundamentales bien desglosado y que, por su alto rango, son pilares del Derecho, por lo que con el contenido de cada uno de esos derechos humanos principales se va a dibujar la esencia inquebrantable de la dignidad.

Reconforta encontrar en la relación de derechos fundamentales una educación integral del hombre que pasa por abrazar el deporte rellenando los trazos principales de esa labor educativa. Con ello también se comprende que el respeto a la dignidad sea un prius, puesto que estamos ante un concepto meta-jurídico, en tanto antecede y trasciende a lo 'positivizado', doblegando al Derecho para que respete lo que viene dado por naturaleza y que se brinda, no como una opción, sino como un informador necesario, para su reconocimiento, realización y enriquecimiento por parte de los poderes públicos y los ciudadanos, es decir, con eficacia erga omnes. Consecuentemente, el respeto a la dignidad humana no se aquieta en un sencillo statu quo, sino que sumerge a la sociedad (Estado, persona y colectivos educativos) en un proceso dinámico para que, con el desarrollo de esos derechos fundamentales, $y$, por ende, con la labor educativa, se posibilite visualizar la dignidad según ese itinerario de perfeccionamiento, que es necesario en el obligado desenvolvimiento de la personalidad. 
Pero la dignidad humana es anterior a su plasmación en el ordenamiento jurídico; la dignidad humana puede ser entendida como una expresión de la belleza misma. Inspirada en el personalismo, y con el magisterio de Juan Pablo II, la dignidad del cuerpo, se identifica con la de la persona (Hernández, ibíd.: ibídem).

Para Patrício (1993), no hay formación del hombre que no contemple el cuerpo; en este sentido, el deporte puede ser una experiencia de espiritualidad. El cuerpo es interpretado en el deporte desde distintas perspectivas, siendo muy alejadas entre sí, pero igualmente respondiendo al mismo como locus de experiencia. En este sentido, Juan Pablo II, nos recuerda «la grandeza y dignidad del cuerpo humano", la obra maestra de toda la creación, «no solo por su proporción, vigor y belleza, sino también, y sobre todo, porque Dios ha hecho de él morada e instrumento de un alma inmortal, infundiéndole ese "soplo de vida" (cf. Gén 2, 7)" (1981).Y al deporte le corresponde la visión serena de la dignidad del cuerpo, porque, advierte Juan Pablo II, «sois auténticos atletas cuando os preparáis no solo con el entrenamiento de vuestros cuerpos, sino también con el acoplamiento constante de las dimensiones espirituales de vuestro ser para lograr un desarrollo armonioso de todos vuestros talentos humanos» (1987: 20). Si damos la espalda a esta visión del cuerpo, corremos el riesgo de convertirlo en un ídolo, lo que puede justificar muchos de los abusos que vemos a diario: dopaje, desprecio de los débiles y deformes, sensualismo, idolatría, etc.

Joseph Ratzinger (2004), explicó perfectamente la aparente paradoja que se da en la figura de Jesucristo, ser «el más bello de los hombres» y, al tiempo, "sin aspecto atrayente, despreciado y evitado de los hombres»; se trata de un contraste, no de una contradicción. Porque «la belleza es la verdad y la verdad es la belleza, pero en el Cristo sufriente también aprende que la belleza de la verdad contiene la ofensa, el dolor e incluso el oscuro misterio de la muerte, y que esto solo puede ser encontrado cuando se acepta el sufrimiento, no cuando se le ignora» (2004: 34). La visión meramente estética de la belleza, en la figura de Jesucristo, durante la Pasión, queda superada (2004: 40):

Aquel que es la Belleza misma se dejó abofetear y escupir el rostro y coronar con espinas [...]. Pero justamente en el rostro tan desfigurado se manifiesta la verdadera y definitiva belleza, la belleza del amor que avanza "hasta el fin» y que se muestra en esto más fuerte que la mentira y la violencia. 
Es por ello que no debemos caer en la mentira de «la belleza engañosa y falsa, una belleza deslumbrante [...] que los encierra (a los hombres) totalmente en ellos mismos. Es la belleza que no despierta el anhelo por lo inefable, ni disposición para el sacrificio, ni el abandono de sí mismo, sino que excita la avidez, la voluntad de poder, de posesión y de placer» (Ratzinger, ibíd.: 40-41).

La dignidad es inherente al ser humano, por naturaleza, y está asociada a la autoconciencia reflexiva y a la libertad que lo caracterizan, y que puede desarrollarse o limitarse en virtud de sus acciones y decisiones.A través de la práctica deportiva, el ser humano busca una plenitud física que redunde en su plenitud humana.

Como bien indica Tomás Bolaño, el atleta, antes que atleta, es una persona humana $\mathrm{y}$, por tanto, es «capaz de querer afirmar lo que es conforme a lo bello, a lo verdadero y a lo bueno» (1991). Porque para Juan Pablo II, a través de la práctica deportiva, en virtud del valor de la dignidad del cuerpo, el ser humano se forma física y espiritualmente en las virtudes de la fe, la esperanza y la caridad (1959: 280).

La estética, en cuanto «ciencia que trata de la belleza» (RAE, 2014), está llamada a representar un importante papel en el campo de la formación ética o de los valores (Barraca, 2011). La educación estética remite a educar en y por la belleza, a desarrollar la sensibilidad hacia lo bello, entendido como un valor excelso ligado a lo bueno. Así los Maestros de la espiritualidad, en su camino hacia la perfección, han confiado en la estética de la iconografía para recrearse en su belleza y alcanzar la más sublime inspiración. No es otro el objetivo de la Tesis de Ángel Moreno, al tratar a Santa Teresa como «amiga de imágenes», aunque afirmando siempre que todo se desnaturalizaría si se agotara en esa sola manifestación de la belleza, que habrá de operar como un servidor no como un señor, aunque sea útil recorrer su senda en tanto llega antes la estética que la ética (Moreno, 2007: 162).

Tempranamente, Baumgarten -Aestbetica, 1750- definió estética como analogon rationis, lo que hace que la belleza descanse en la subjetividad de un conocimiento o una vivencia que obedece a la capacidad interna del conocimiento. La estética puede definirse como la ciencia que estudia el conocimiento que adquirimos a través de los sentidos, siendo la belleza uno de sus objetos de estudio. Bello sería aquello que agrada a los sentidos y puede llevar a sentimientos de atracción y bienestar emocional (San Agustín); y belleza, es aquello que nos procura sensación de placer a través de los sentidos. 
A lo largo de la historia de la filosofía el tema de la belleza se ha abordado de diferentes formas, que presentamos someramente en la siguiente tabla desde una perspectiva «filocristiana» (Martínez, 2012):

\section{Tabla 1}

Visión de la belleza en el pensamiento filosófico «filocristiano»

\begin{tabular}{|c|c|}
\hline Autor & Concepto de belleza \\
\hline Pitágoras & Simetría y proporción \\
\hline Protágoras & Relativa a cada individuo \\
\hline Sócrates & $\begin{array}{l}\text { «elleza espiritual», algo más que física. Belleza como conve- } \\
\text { niencia, adecuación a una utilidad: el bien moral (Hippias } \\
\text { Mayor); amor ideal (Fedro); Inclinación a la perfección; la ver- } \\
\text { dad (Banquete) }\end{array}$ \\
\hline Aristóteles & $\begin{array}{l}\text { Proporciones perfectas; lo que agrada o es valioso en sí mismo. } \\
\text { La belleza es buena; no todo lo bueno es bello }\end{array}$ \\
\hline $\begin{array}{l}\text { Protágoras y } \\
\text { Gorgias }\end{array}$ & $\begin{array}{l}\text { Felicidad es igual a virtud (dominio de las pasiones): belleza } \\
\text { moral; la naturaleza es bella }\end{array}$ \\
\hline Plotino & La Belleza está en el alma, en el interior, no en las formas \\
\hline $\begin{array}{l}\text { Pseudo } \\
\text { Dionisio }\end{array}$ & Belleza como bondad \\
\hline Cicerón & Belleza estética (sensorial) / belleza moral (espiritual) \\
\hline $\begin{array}{l}\text { Pseudo } \\
\text { Longino }\end{array}$ & Distingue bello de sublime (lo sublime sorprende) \\
\hline Lactancio & Lo feo es bello si es útil \\
\hline Edad Media & Lo importante es el símbolo, el significado, más que la forma \\
\hline San Basilio & Bello es lo que cumple una utilidad \\
\hline San Agustín & En cada fragmento de la naturaleza está Dios \\
\hline Santo Tomás & Belleza y bondad son lo mismo \\
\hline Dante & El amor es la fuente de belleza \\
\hline Luca Pacioli & «Proporción áurea» (número fi) que se cumple en todo \\
\hline
\end{tabular}


La estética hace referencia a una filosofía del arte, por lo que sienta las bases epistemológicas del conocimiento de lo bello. En la Grecia clásica, lo bello tenía fuertes implicaciones en el ámbito educativo. Lo kalos era «aquello digno de reconocimiento en virtud de su apariencia, aquello excelso por ser hermoso» (Siabra, 2007: 2); de ahí que la kalos agatbos -kalós: bello; agathós: bueno- se refería al perfecto caballero, y la kalokagathía, a la conducta de dicha persona. En este sentido, ese ideal clásico debe ilustrar la labor educativa de profesores y entrenadores; contribuyendo desde la educación física a la formación integral del alumno, porque «el arte que busca en el juego su salvación de la apariencia se pasa al deporte» (Adorno, 1970: 179).

También debemos conectar la estética con el ámbito de lo lúdico (Barraca, 2011), revitalizando el hondo análisis que de lo lúdico hace Huizinga (1972) al ponerlo en relación con el arte, la contemplación y la experiencia estética.

En este sentido, la educación física puede entenderse como el arte de construir y modelar al ser humano tomando como arcilla su capacidad natural de movimiento. Al dirigir sus movimientos, proponiendo la exploración como herramienta de desarrollo de una motilidad intencional, estamos formando e informando al alumno desde los valores de la libertad y la creatividad.

\section{CAMINO: PARA UNA EDUCACIÓN ESTÉTICA}

La educación física, a través del desarrollo de algunos de los contenidos que le son propios (el deporte y los juegos), está llamada a ser uno de los bastiones defensivos de los valores estéticos vinculados a lo bello. La belleza del gesto deportivo ha sido cantada tanto por Ulrich (2005), en su Elogio de la belleza atlética, como por Serrano (1991), en su Elogio de la pasión pura, en ambos casos destacando el asombro que producen las gestas deportivas en quienes disponen de la sensibilidad necesaria para admirarlas.

Ulrich nos invita a admirar no solo a los deportistas, sino también sus proezas, las cuales debemos elogiar, puesto que son bellas. De ahí surge la experiencia estética, a través de la observación y del placer que esta provoca. Se trata de una satisfacción desinteresada, ya que «no tendrá nunca una utilidad objetiva en su vida cotidiana» (2005: 42). Bajo la fórmula «estar perdido en la intensidad de la concentración» (ibídem: 52), Ulrich conjuga 
la fascinación de ver deporte con el atractivo de practicarlo. Nos invita a percibir el deporte desde una perspectiva kantiana que puede explicar la maestría deportiva en tanto en cuanto ese «estar perdido» conecta con el carácter desinteresado del juicio estético (Kant, 1999).

Esta experiencia da fe de la comunión entre el espectador y el actor a través del espectáculo deportivo. Imaginándose la acción de su ídolo antes de que este la ejecute, el espectador activa las mismas zonas neuronales que pondría en juego si de hecho fuese él quien la ejecutase, mediante un proceso similar al definido por Damasio (2009), a propósito de las neuronas reflejo.

Por ello, los docentes deben introducir al alumno en el disfrute estético del deporte, en la empatía y la admiración del gesto deportivo, como alegoría de los mitos básicos vinculados al movimiento: saltar, volar..., desafiando a las leyes físicas que sujetan al hombre en virtud de la gravedad.Y es que el recurso a la belleza, su cultivo, no es una opción sino una necesidad para localizar la manifestación de lo sublime, en particular en las realidades que se acotan, como la deportiva, que es materia propia de la educación, permitiendo una vis atractiva para sumergir al hombre en su complejo proceso de dignificación, donde ha de atenderse la educación y, por ende, la educación deportiva. Esta, en efecto, corresponde a los docentes y entrenadores, que no la imparten de cualquier forma sino desde un compromiso ético y estético, siguiendo la estela de los valores y la belleza, donde reside, en el fondo y en la forma, la excelencia de su contenido. Si bien, antes que a estos enseñantes, es al padre al que se le reconoce el derecho y la exigencia de procurar al hijo una educación integral por la que siembre y perpetúe unos valores morales, para luego vincular en esta tarea educativa a ese tercero que es el docente. Ambos educadores han de verse invitados a perseguir unos cánones de belleza para hacer de su encomienda un trayecto de más fácil recorrido, en cuanto va a ser querido por el educando, inquietado y llamado al conocimiento.

Sin embargo, algunos discursos en torno a la función de la educación física en la escuela han situado a esta disciplina en una posición de meritocracia reduccionista, ligada exclusivamente al rendimiento. Basándose en modelos mecanicistas, se ha propuesto una imagen de alumno que reproduce por imitación gestos técnicos estereotipados. A pesar de la atracción que genera la reproducción mimética de ciertos movimientos, el alumno debe percibir igualmente la belleza de las formas y los movimientos creativos, intuitivos, libres y desinteresados. 
Cuando hablamos de belleza en el deporte, debemos atender a una graduación, que distingue un primer nivel, relativo a los sentidos externos, esto es, la belleza misma del cuerpo en movimiento, las formas, la dificultad, etc.; de otro, relativo a la dimensión interior del ser humano: capacidad de sacrificio, superación, compañerismo, respeto al rival, etc. En este sentido, el hacer todo lo posible por alcanzar las metas, independientemente del resultado, dando lo mejor de uno mismo, aumenta nuestra dignidad humana.

La estética también se conjuga con la creatividad en el deporte, dando lugar a un tipo de arte que propicia la contemplación de la obra deportiva, de la proeza, como dimensión artística. Ahí encontramos distintas manifestaciones del arte que toman como objeto, y como modelo, al deporte. A través de la fotografía, la pintura, el cine o el cómic, el discurso deportivo viste distintos ropajes que lo elevan a la categoría de manifestación artística, como objeto que dota de expresión y contenido a las distintas artes.

Esa capacidad creativa del ser humano se manifiesta tanto en la técnica como en la táctica deportiva. Los esquemas de juego, la habilidad en la ejecución de un salto o de un remate, la disposición de los jugadores en el campo... Todo ello es una cifra de un modelo de belleza que puede interpretarse en clave trascendente.

Ahí es donde la estética corporal, en su expresividad, eleva la figura casi volátil del gimnasta o del danzarín. Se trata de una belleza de las formas, de los cuerpos e incluso de los ropajes, abriendo un camino de expresión a la posmodernidad que bien puede ilustrar la estética de prácticas posmodernas como el hip-hop. Todo ello, sin olvidar la belleza interior del deportista, a veces oculta, pero que es la que verdaderamente importa.

En todo caso, podemos entender la estética como «la reflexión filosófica sobre la belleza y el arte, y como un valor humano significativo» (Garcia y Lemos, 2005: 26), vinculado a lo bueno y lo bello. En este sentido, el profesor de educación física, debe ser un «esteta», una "persona que considera el arte como un valor esencial» (RAE, 2014), con inclinación hacia el culto de la belleza.

Esa tendencia hacia el cultivo de la belleza a través del gusto estético, debe llevarle a buscar en el alumno su máximo desarrollo personal -físico, ético, moral y social- haciéndolo compatible con el encuentro personal de la eudemonía. Para conquistar este estado, que fue descrito por Ortega y Gasset (1996) al referirse al deporte como «ocupación felicitaria», es preciso alcanzar previamente cierta armonía, un equilibrio personal que atañe a la complejidad del ser humano. 
La escuela es corresponsable de la educación del niño. Dentro de sus objetivos se encuentra la educación estética para desarrollar en él la virtud del respeto y el aprecio de lo bello. Sin embargo, en la sociedad actual de posmodernidad (Sánchez y Mosquera, 2011: 100-102), la tiranía de ciertos modelos corporales (de decadencia), exhibidos por la figura caricaturizada de hombres y mujeres excesivamente delgados, musculados, anoréxicos o 'vigoréxicos', ha llevado a considerar el deporte como una herramienta modeladora del cuerpo, cuyo reflejo es una escuela que educa en (contra) valores de aislamiento, del todo vale, de la búsqueda de la fama, el individualismo, del usar y tirar, etc. (Mosquera y otros, 2004: 63-71). Esta perspectiva parte del modelo de hombre máquina, el cual puede ser moldeado según gustos y apetencias para alcanzar el canon socialmente deseable.

La educación física aspira al patrimonio y al señorío de parte de la educación estética. Puede y debe alcanzarlo sobre la base del juego, reivindicando los componentes lúdico, hedónico y agónico que a él subyacen, desde un perspectiva posmoderna de resistencia donde primen actitudes y comportamientos de juego limpio, no violencia, cooperación y competición (Mosquera y otros, 2004: 71-77).

Existen dos escuelas filosóficas sobre el concepto de gusto, como eje de reflexión en torno a la teoría estética: una, de carácter sensualista-empirista, centrada en la fisiología y la psicología de la belleza; otra, racionalista, que busca la perfección formal de una obra de arte en relación al entendimiento (Schiller, 2005: VII). En el deporte pueden conjugarse ambas perspectivas, la sensualista, accesibles por los ojos, y la racionalista, en la valoración del gesto deportivo en toda su intensidad y grandeza. A ellas, debe acoplarse una compresión de la corporeidad de raíz personalista, próxima a la expuesta por la teología cristiana de Juan Pablo II, en su teología del cuerpo.

La acción educativa opera sobre el alumno de forma quirúrgica, directa a la parte afectada. No se trata de una cirugía de tipo estética -esto es: plástica-, en el sentido de embellecer alguna parte del cuerpo, sino de intervenir sobre el alumno en su totalidad, como persona humana, para salvaguardar su dignidad frente a los abusos de lo corporal desde una perspectiva reduccionista. El docente debe ayudar a construir personas bellas, que complacen a quien las observa y les produce deleite y placer espiritual. Personas completas, equilibradas, que se conocen y se dejan conocer, que saben experimentar y convivir, disfrutar y contagiar de emoción a los demás. Personas sanas, amables, joviales... deportistas. 
A los niños, a los jóvenes, el juego les ayuda a tomarse las cosas -la vidaen serio, pues nada hay más serio que el juego (Huizinga, 1972).Y junto al juego, el deporte coadyuva en la aceptación de los límites, en primer lugar porque permite conocerlos y, posteriormente, porque se experimentan.

La educación física debe ayudar al joven a aceptar su cuerpo vivo, cambiante, socializado, que siempre progresa, aunque merme sus facultades desde una perspectiva cuantitativa; que se hace más económico, eficiente, según avanzan los años. Debe ayudarle a aceptar el paso del tiempo y su impronta en el cuerpo, como reflejo de su alma y de su estado de ánimo; en suma: de su personalidad. Debe enseñar al alumno a que hay un cuerpo para cada edad, como hay una mente, y que ambos actúan bajo unicidad, congruencia, acompasados, por lo que deben evitar caer en el anacronismo de pretender un cuerpo joven en una persona adulta, porque ello aboca al dualismo, no a la armonía y la belleza. No hay nada más estético que el efecto del paso del tiempo en el ser humano. Nada más kitsch que la asincronía de un cuerpo terso, quirúrgico, limitando la expresividad de un alma colmada por los años.

Pero al inculcar en nuestros alumnos el amor y el gusto por el juego y el deporte y, con ello, por el cuidado del cuerpo, entendido como vehículo de experiencias, les estamos proponiendo valores estéticos que dejan huella en su morfología, en sus movimientos, sus disposiciones. Porque un cuerpo prematuramente envejecido ya no es funcional, útil ni bello. Necesitamos de la educación física como del alimento, para alcanzar el máximo de nuestras potencialidades.

En ese sentido, el efecto del trabajo sobre el cuerpo -corporeidad-, como sobre la mente (Sánchez y Gutiérrez, 2012: 5-18) -intelectualidad-, dignifica al hombre, como lo hace simétricamente el ejercicio físico con fines lúdicos -deportivos. Vivir intensamente desgasta, oxida nuestras células, deja huellas, que son como los anillos de un árbol que nos indica su edad. No una edad cronológica, sino existencial. Pero es preciso que ese crecimiento sea armonioso, y sin juego, sin deporte, sin arte, sin lectura, etc., no se puede alcanzar.

La actividad deportiva, como la filosófica, es desinteresada, acaso no es útil, y por ello es estética. Para Barraca (2011: 2009), en lo estético hay una dosis de juego, «destella siempre un anhelo de olvidar nuestro afán rutinario, una pausa en lo inmediato y urgente, un tiempo de "contemplación”, un goce en la propia actividad más allá de sus utilidades exteriores». 
El teólogo bizantino Nicolás Kabasilas (s. XIv) distingue dos tipos de conocimiento: uno, mediante la instrucción -de segunda mano-, que no implica contacto directo con la realidad misma; otro, mediante la propia experiencia y la relación directa con las cosas, porque hasta que no hemos tenido la experiencia de un ser concreto, "no amamos al objeto tal y como debería ser amado» (Ratzinger, 2004: 36). Este es el tipo de conocimiento que tenemos que hacer accesible a nuestros alumnos a través de la experiencia del juego y el deporte en la educación física. Porque «Si conocemos no solamente a través de meras palabras, sino al ser heridos por la flecha de su belleza paradójica, entonces aprendemos a conocerlo realmente y a saber de él no solo de segunda mano. De este modo hemos encontrado la belleza de la Verdad, de la Verdad que redime» (2004: 41).

Es la estética, en cuanto disciplina, la que debe llevarnos al entendimiento de la unidad indisoluble del ser humano, a la perfección no solo de las formas, sino del hacer y el sentir, porque «nos invita a apuntar hacia esa inefable comunión de lo único» (Barraca, 2011: 217). Por eso, la belleza a que apunta la educación física, dentro de la educación del alumno, está sustanciada en la paideia.

La paideia representaba el camino para integrar el mundo y la vida en un mismo proceso (González, 2009: 70), simbolizado por las obras artísticas que con la perfecta armonía de sus partes alcanzaban la belleza. Tal relación entre el mundo y la existencia resulta fundamental para entender hoy el deporte. Este, encarna el mundo de la vida, ayuda a encontrar el lugar que uno ocupa en él y, por lo tanto, contribuye a otorgarle un sentido. La armonía de las partes, en su conjunto, constituye la esencia de la educación física, la cual, a su vez, es cifra de una armonía lógico-trascendente. Difícilmente se puede expresar mejor de como lo hizo Juan Pablo II (1990):

\footnotetext{
No es solo el campeón del estadio, sino el hombre en la totalidad de su persona quien debe convertirse en un modelo para millones de jóvenes, los cuales tienen necesidad de 'lideres' y no solo de 'ídolos'. Tienen necesidad de hombres que sepan comunicarles el sabor de lo difícil, el sentido de la disciplina, la valentía de la honestidad y la alegría de afrontar los problemas de la vida con mucho empeño y entusiasmo.
}

Si bien «el deporte, recuerda a ocupaciones prácticas y cumple la función de acostumbrar a los seres humanos a las exigencias de la praxis» (Adorno, 1970: 409), en la actualidad, el profesor, que ayuda al niño en la plasmación permanente de su ser natural, está representado por el entrenador, que enseña a otros una téchne -como saber científico-racional- ale- 
jada del proceder mecanicista y repetitivo que busca la producción de objetos útiles. Según González, se busca de este modo la superación «en respetable responsabilidad que permite el ejercicio de las libertades, obligadamente compartidas como ejercicio de un pensamiento reflexivo y crítico que pone a los hombres y a las cosas en su sitio» (2009: 70).

Esta función moderna del deporte ya fue privilegiada por Ortega y Gasset (1996: 610), cuando se refería a él como un esfuerzo superfluo que constituye, no obstante, la actividad «más elevada, seria e importante en la vida». Esta actividad estaba representada, nos recuerda Ortega, por los atletas griegos y la askesis que era «el régimen de vida del atleta, llena de ejercicios y privaciones» (ibídem: 617); su antecedente se encuentra en el origen deportivo del Estado. Cuando Ortega considera al deporte un lujo vital, lo coloca al nivel de la filosofía, dentro de aquellas actividades lujosas, no útiles ni prácticas, pero decisivas, por la importancia de las experiencias que en ellas se adquiere; actividades que después se trasladan a la vida con gran valor. En este sentido, tanto la filosofía como el deporte son hermenéuticas que ayudan a transmitir y a experimentar en 'carne propia' cuestiones a priori obscuras.

\section{EPÍLOGO: ¿DE QUÉ BELLEZA HABLAMOS A NUESTROS ALUMNOS?}

Dicho lo anterior, a nuestros alumnos y deportistas debemos hablarles de una belleza que tiene utilidad, es sublime, actúa por bondad, no se limita a las formas, es ideal, es simbólica. La búsqueda de belleza, separada de la búsqueda de la bondad y la verdad lleva al «estetismo», desemboca en lo efímero, banal, superficial, vacío de contenido y sinsentido (Ratzinger, 2002).

El ser humano es, para Juan Pablo II, un ser corporal, pero «por material que sea, el cuerpo no es un objeto como otro cualquiera. Es, ante todo, alguien; en el sentido de que es una manifestación de la persona, un medio de presencia entre los demás, de comunicación...» (Hernández, 2004: 431). Por ello, Juan Pablo II nos exhorta a que jamás caigamos en la adoración o en el desprecio del cuerpo, sino en su dominio y transfiguración.

En este sentido, la belleza artificial es un camino errado, lo que ha llevado a Juan Pablo II a criticar las degradaciones corporales de la persona durante el siglo xx. La belleza trasciende lo exterior, tiene una dimensión moral -lo bueno. Si bien es cierto que la belleza se plasma culturalmente 
en distintas formas, existe una belleza con mayúsculas. Para la Teología, la belleza es pasión -de Cristo-, belleza del amor que llega hasta el extremo: "pero en el Cristo sufriente comprende también que la belleza de la verdad incluye la ofensa, el dolor e incluso el oscuro misterio de la muerte, y que solo se puede encontrar la belleza aceptando el dolor y no ignorándolo» (Ratzinger, 2002). Ratzinger (2004: 34-41) destaca que el hombre perfecto es Jesucristo, y que es tanto el más bello de los hombres como que no es grato mirarle. Esta aparente contradicción se resuelve cuando comprendemos que la belleza de que nos habla no es física, corporal en un sentido exterior, sino interior, plena y verdadera; la de la aceptación del destino, la consumación de una obra, un plan, el plan Divino de la muerte y resurrección.

Porque «la belleza es conocimiento, ciertamente; una forma superior de conocimiento, puesto que toca al hombre con toda la profundidad de la verdad» (Ratzinger, 2002). Este es el concepto de belleza que tenemos que trasmitir a nuestros alumnos y que se plasma en el deporte, entendido este como una actividad humana (ética en sí misma y que se desarrolla en un escenario lúdico y saludable, permitiendo el abundamiento estético), que dignifica al hombre, más allá de sus limitaciones o condiciones de práctica -disminuidos, deficientes, mayores, gruesos, flacos, etc. -. En efecto, a nuestros alumnos hay que trasladarles lo sublime para conseguir garantizar la atracción pura o, lo que es lo mismo, su amor al conocimiento. En cuanto el deporte, como portador de belleza y valores (de belleza corporal y de belleza espiritual), dota necesariamente de contenido a la educación integral, y se sabe garantizado y tutelado por el derecho fundamental a la educación. El cuadro de derechos fundamentales preserva la dignidad inherente al ser humano y asegura el libre desenvolvimiento de dicha dignidad a través de instituciones como la educación y el deporte.

Una dignidad que se manifiesta junto a la belleza humana cuando se asumen libremente tanto el dolor como el sacrificio, el cansancio o las lágrimas propias de las gestas deportivas. Porque el camino para alcanzar la perfección o la excelencia, se transita con esfuerzo. De este modo, aprendemos a aceptar las limitaciones, incluidas las lesiones propias del deporte, como Jesucristo aceptó la Cruz. Porque la búsqueda de la verdad y el bien no está exenta de dolor, tanto en el deporte como en la vida en general.

Solo entonces, con el recurso a la belleza, se añade a la dignitas la bumanitas, y ambas, cuando se encuentran en equilibrio, hacen de las personas seres excepcionales. Un ejemplo excelso de esta sinergia nos lo brindó el formidable boxeador Mohamed Alí -antaño invencible- en su caminar 
lento, titubeante, a causa de su avanzado párkinson, al portar la antorcha olímpica en los Juegos de Atlanta en 1996; otro, Juan Pablo II, gran amante del deporte durante toda su vida, cuando, en sus últimos días, mostró públicamente su humanidad en su enfermedad, sin perder en ello su excelencia o dignidad. Es la belleza de quien ha alcanzado la meta, la consumación de una vida.

Porque, como nos recuerda Tomás Bolaño, aquella mañana de miércoles de pascua de 2005, en su ventana al mundo, como el más grande corredor de largo aliento, Wojtyla, no solo exhibió su fortaleza física, cuando traspasaba la línea final de su carrera; sino que también demostró la templanza espiritual como el Atleta de Dios, que al finalizar su trayecto saca sus mejores y últimos alientos para atravesar victorioso la línea final de la meta que demarca la sutil división entre el límite de la vida y la eternidad.

\section{REFERENCIAS}

Adorno, T.W. (2004): Teoría estética, Madrid, Ediciones Akal.

BARraca MaIral, J. (2011): «Estética y formación humana: el valor de la estética en la educación», Educación y Futuro, 24, pp. 205-219.

Baumgarten, A. G. (1986): Aesthetica, Hildesheim, Georg Olms.

Bolaño Mercado,T. E. (1991):Juan Pablo II y el deporte. Disponible en http://www. tomasbolano.com/index.php?option=com_content\&view=article\&id=147:juanpablo-ii-y-el-deporte\&catid=35:teologia-del-deporte\&Itemid=64

Cagigal, J. M. (1959): «Aporías iniciales para un concepto del deporte», $\mathrm{C} i$ tius, Altius, Fortius, 1 (I), pp. 7-35.

Damasio, A. (2009): El error de Descartes, Drakontos, Barcelona.

Garcia, R. y Lemos, K. (2005): Temas (quase éticos) de Desporto, Belo Horizonte, MG, Casa da Educaçâo Física.

GonZÁlez Jiménez, F. E. (2009): «El Magisterio: una mirada sobre el tránsito de la Paideia al idealismo», Tendencias Pedagógicas, 14, pp. 63-85.

HernÁNDEZ URIGÜEN, R. (2004): «Hacia la corporeidad gloriosa.Apuntes teológicos para una estética del cuerpo desde el magisterio de Juan Pablo II», en, Saranyana, J. I., Gil, J. A., Rosario, M. ${ }^{a}$, Flandes, E. y Casas, S. (coord.) (2004): El caminar bistórico de la santidad cristiana: de los inicios de la época contemporánea basta el Concilio Vaticano II, Pamplona, Universidad de Navarra, Servicio de Publicaciones.

Huizinga, J. (1972): Homo Ludens, Madrid, Alianza. 
Juan Pablo II (1980): «Discurso a los deportistas del Sporting Club de Pisa» en Insegnamenti di Giovanni Paolo II, Vol. III, 2, p. 1678.

- (1981, 11 de octubre): "A los participantes en los XIII Juegos de la Juventud» en Kevin Lixey, L. C. (ed.) (2012): El Beato Juan Pablo babla con deportistas. Discursos, bomilias, y mensajes relacionados con el deporte, Roma, Consejo Pontificio para los Laicos, Fondazione Giovanni Paolo II per lo Sport.

- (1981, 26 de marzo): «Discurso a los miembros del congreso del Panathlon Internacional», Roma, L'Osservatore Romano, Edición de lengua española.

- (1987, 2 de septiembre): «Discurso al campeonato de atlética ligera "El deporte favorece la fraternidad y entendimiento entre los pueblos"», Roma, L'Osservatore Romano, Edición en lengua española.

- (2000, 28 de octubre): "Discurso al Congreso Internacional de Jubileo de los Deportistas», en Kevin Lixey, L.C. (ed.) (2012): El Beato Juan Pablo babla con deportistas. Discursos, bomilías, y mensajes relacionados con el deporte, Roma, Consejo Pontificio para los Laicos, Fondazione Giovanni Paolo II per lo Sport.

Juan Pablo II (2004, 26 de junio): «Discurso a los miembros del centro deportivo italiano en el 60 aniversario de su fundación», en Kevin Lixey, L. C. (ed.) (2012): El Beato Juan Pablo habla con deportistas. Discursos, bomilías, y mensajes relacionados con el deporte, Roma, Consejo Pontificio para los Laicos, Fondazione Giovanni Paolo II per lo Sport.

JUAN XXIII (1959): «Rallegramenti per il Centro Sportivo Italiano» en Discorsi, Messaggi, Colloqui I.

JUAN XXIII (1995, 7 de septiembre): «Discurso a los participantes en los juegos mundiales militares "Guerra a las guerras" ", Roma, L'Osservatore Romano, edición en lengua española.

Kant, I. (1999): Crítica del juicio, Madrid, Espasa-Calpe.

MARTÍnez, J. (2012): La búsqueda de la belleza: un viaje al interior del ser bumano, Conferencia dictada el 26 de marzo, Universidad Católica San Antonio de Murcia.

Moreno, A. (2007): La imagen de Cristo en la Contemplación de Santa Teresa de Jesús, Burgos, Monte Carmelo.

Mosquera González, M. ${ }^{a}$ J. y otros (2004): No violencia en el deporte y en la vida. Guía para docentes y personas interesadas, Xunta de Galicia, Dirección Xeral para o Deporte, Consellería de Familia, Xuventude, Deporte e Voluntariado. 
Mosquera González, M. ${ }^{a}$ J. y Sánchez Pato,A. (2011): Tratado sobre violencia $y$ deporte. La dialéctica de los ámbitos intercondicionantes, Sevilla, Wanceulen.

Mosquera, M. a J. y SÁnChez,A. (2007): «Sport Culture of 'Nonviolence' in Sport and Life: Educational Guide. The Code of 'Nonviolence'» en Hannu ItKoNEN, H. y otros (eds.) (2007): The Changing Role of Public, Civic and Private Sectors in Sport Culture, Jyväskylän, Finlandia, University of Jyväskylä, Department of Sport Sciences Publications.

Ortega y Gasset, J. (1996): Obras Completas (vol. II, pp. 607-624), Madrid, Revista de Occidente.

Patrício, M. F. (1993): Lições de Axiologia educacional, Lisboa, Universidade Aberta.

Quintana Domínguez, J. M. (2011): El beato Juan Pablo II: un Papa deportista y un deportista Papa, Pontificio Consejo para los Laicos. Disponible en http://www.laici.va/content/laici/es/sezioni/chiesa-e-sport/notizie/ giovanni-paolo-ii--un-beato-sportivo-.html

RATZINGER, J. (2002): La contemplación de la belleza, Mensaje del cardenal Ratzinger a los participantes en el «Meeting» de Rímini, Italia. Disponible en http://multimedios.org/docs/d001310/

-(2004): Caminos de Jesucristo, Madrid, Ediciones Cristiandad.

Real ACADEmia Española (2014): Diccionario de la lengua española (23 ed.), Madrid, España, Autor.

SÁnchez Pato,A. y Gutiérrez Arranz, J. M. (2012): «Mind and body versus Gymnastics and philosophy: from dualism to emergentism», Cultura, Ciencia y Deporte, 19, pp. 5-18.

SCHILLER, F. (2005): Kallías; Cartas sobre la educación estética del bombre, Barcelona, Anthropos Editorial.

SErrano Farrera, S. (1991): Elogio de la pasión pura, Madrid, Planeta.

Siabra Fraile, J. (2007, octubre): «La perversión del legado griego: kalokagatbía y mutilación en la Ilíada y 300» en Congreso Iberoamericano: Influencia de las Éticas Griegas en la Filosofía Contemporánea, Madrid, Universidad Autónoma de Madrid.

Ulrich Gumbrecht, H. (2005): Elogio de la belleza atlética, Buenos Aires, Katz Editores. 